\title{
The impact of anesthesia providers on major morbidity following screening colonoscopies
}

This article was published in the following Dove Press journal:

Journal of Multidisciplinary Healthcare

28 May 2015

Number of times this article has been viewed

\author{
David A Lubarsky' \\ Jason R Guercio² \\ John W Hanna ${ }^{3,4}$ \\ Maria T Abreu ${ }^{5}$ \\ Qianli $\mathrm{Ma}^{3}$ \\ Claudia Uribe ${ }^{3}$ \\ David J Birnbach 1,6 \\ David R Sinclair' \\ Keith A Candiotti' \\ 'Department of Anesthesiology, \\ Perioperative Medicine and Pain \\ Management, University of Miami - \\ Miller School of Medicine, Miami, FL, \\ USA; ${ }^{2}$ Department of Anesthesiology, \\ Duke University, Durham, NC, \\ USA; ${ }^{3}$ Humana, Comprehensive \\ Health Insights, Miami, FL, USA; \\ ${ }^{4}$ University of Miami - Miller School \\ of Medicine, Miami, FL, USA; \\ ${ }^{5}$ Department of Medicine, Division \\ of Gastroenterology, University of \\ Miami - Miller School of Medicine, \\ Miami, FL, USA; ${ }^{6}$ Department of \\ Public Health Sciences, University of \\ Miami - Miller School of Medicine, \\ Miami, FL, USA
}

Correspondence: David R Sinclair Clinical Anesthesiology, University of Miami - Miller School of Medicine, 16II NW 12th Avenue, JMH Central I30, Miami, FL, USA

$\mathrm{Tel}+\mathrm{I} 305689$ I227

Fax +l 3055857002

Email dsinclair@med.miami.edu
Background and aims: Few studies evaluate the impact of anesthesia providers during procedures, such as colonoscopy, on low-risk patients. The objective of this study was to compare the effect of anesthesia providers on several outcome variables, including major morbidity, following screening colonoscopies.

Methods: A propensity-matched cohort study of 14,006 patients who enrolled with a national insurer offering health maintenance organization (HMO), preferred provider organization (PPO), and Medicare Advantage plans for a screening colonoscopy between July 1, 2005 and June 30, 2007 were studied. Records were evaluated for completion of the colonoscopy, new cancer diagnosis (colon, anal, rectal) within 6 months of the colonoscopy, new primary diagnosis of myocardial infarction (MI), new primary diagnosis of stroke, hospital admission within 7 days of the colonoscopy, and adherence to guidelines for use of anesthesia providers.

Results: The presence of an anesthesia provider did not affect major morbidity or the percent of completed exams. Overall morbidity within 7 days was very low. When an anesthesia provider was present, a nonsignificant trend toward greater cancer detection within 6 months of the procedure was observed. Adherence to national guidelines regarding the use of anesthesia providers for low-risk patients was poor.

Conclusion: A difference in outcome associated with the presence or absence of an anesthesia provider during screening colonoscopy in terms of MI, stroke, or hospital admission within 7 days of the procedure was not observed. Adherence to published guidelines for the use of anesthesia providers is low. The incidence of completed exams was unaffected by the presence of an anesthesia provider. However, a nonstatistically significant trend toward increased cancer detection requires further study.

Keywords: safety, complications, myocardial infarction, stroke, endoscopy, anesthesiology

\section{Introduction}

Colorectal cancer is the third leading cause of cancer death among men and women in the US. In 2009, an estimated 146,970 cases were diagnosed and an estimated 49,920 deaths occurred. ${ }^{1}$ Current colon cancer prevention guidelines from the American Cancer Society are for average-risk men and women over 50 years of age to receive a flexible sigmoidoscopy every 5 years, a colonoscopy every 10 years, a double-contrast barium enema every 5 years, or a computed tomography colonography every 5 years to identify the presence of precancerous adenomatous polyps and detect colon cancer. ${ }^{2}$ Despite these recommendations, screening colonoscopies remain uncommon. An estimate by the Behavioral Risk Factor Surveillance System in 2001 estimated that only $47.3 \%$ of adults above the age of 50 years had ever undergone a lower endoscopy. ${ }^{3}$ 
Since screening colonoscopies are recommended for a large segment of the American population, the efficient use of resources is essential. ${ }^{4,5}$ Colonoscopies are rarely performed without sedation. ${ }^{6}$ Typically, sedative medications are administered to ensure patient comfort and to decrease awareness during the procedure. The overall cost of providing sedation for the colonoscopy increases if an anesthesia provider is present.

The value of having sedation for screening colonoscopies administered by anesthesia providers (anesthesiologists and/ or certified registered nurse anesthetists [CRNAs]) has been debated. Much of the discussion centers around the use of propofol. Gastroenterologists frequently prefer propofol over other sedatives (such as opioids and benzodiazepines) due to propofol's quick onset and quick offset. The beneficial effect of propofol on throughput is an important consideration for gastroenterologists. ${ }^{7,8}$ However, due to the US Food and Drug Administration's (FDA) restrictions for propofol use exclusively among providers who have been trained in the administration of general anesthesia and not involved in the conduct of the surgical/diagnostic procedure, many gastroenterologists will not use propofol without the presence of a licensed anesthesia provider. ${ }^{9}$ Patients' satisfaction appears equivocal, when choosing between sedation with propofol versus sedation with an opioid and benzodiazepine combination. ${ }^{10}$ However, researchers have stated that the presence of an anesthesia provider improves the quality of sedation and is cost-effective, allowing for a more complete and carefully conducted colonoscopy with improved health outcomes. ${ }^{11}$ Recent studies have challenged these assertions. In a retrospective population-based study of 165,527 procedures in 100,359 Medicare beneficiaries, including 35,128 (21.2\%) who received anesthesia services, Cooper et al demonstrated that anesthesia services were associated with an increased risk of aspiration $(0.14 \%)$ compared to non-anesthesia services $(0.10 \%)(P=0.02) .{ }^{12}$ The increased risk of aspiration was the main factor accounting for the overall increase in complications (perforation and splenic injury) in patients undergoing colonoscopy with anesthesia services $(0.22 \%)$ compared to without anesthesia services $(0.16 \%)(P=0.0001)$.

Mortality following a screening colonoscopy is a rare event. ${ }^{12}$ The overall 30 -day mortality is $0.29 \%$ and was similar in the anesthesia $(0.32 \%)$ and non-anesthesia $(0.28 \%)$ groups $(P=0.29)$. The overall 1 -year mortality was $2.68 \%$ and was also similar in the anesthesia $(2.82 \%)$ and non-anesthesia (2.64\%) groups $(P=0.06)$. Although the absolute risk of 30-day and 1-year mortality was low, the frequency of major cardiac or neurologic morbidity is unknown.

This study evaluates the impact of anesthesia services on major morbidity associated with myocardial infarction (MI) or stroke within 7 days following a screening colonoscopy. In addition, the efficacy, completion rate, incidence of a repeat colonoscopy within 6 months, and incidence of hospital admission within 7 days following a screening colonoscopy were also studied. We hypothesize that the presence of an anesthesia provider during colonoscopy would result in a more complete exam and an associated increased incidence of cancer detection. Additionally, we hypothesize that sedation administered by an anesthesia provider would be associated with fewer serious complications during and after a screening colonoscopy, due to better sedation management skills. Diagnostic outcomes and adverse events associated with the presence or absence of an anesthesia provider in a large population undergoing screening colonoscopies are evaluated. In addition, adherence to the 2004 joint national guidelines published by the American College of Gastroenterology (ACG), American Gastroenterological Association (AGA), and American Society of Gastrointestinal Endoscopy (ASGE) on the use of anesthesia providers during screening colonoscopies is studied.

\section{Methods}

After institutional review board approval, a cross-sectional and retrospective cohort analysis was conducted, using medical and pharmaceutical claims data for a representative population insured through commercial (HMO or PPO) or Medicare Advantage plans administered by Humana, Inc. Three electronic databases were merged. The member file database contained demographic information for each member per encounter (age, sex, type of insurance, and geographical region). The medical file database stored up to nine recorded International Classification of Diseases Ninth revision (ICD-9) codes per encounter, the primary code/reason for the encounter, the Current Procedural Terminology (CPT) codes, the CPT modifiers, and the G codes for procedures. The pharmacy file contained all Generic Product Identifier (GPI) numbers of pharmacy-dispensed medications per claim.

\section{Study population}

Between the identification period of July 1, 2005 and June 30, 2007, patients 50 years of age and older with at least one medical claim containing 45,355, 45,378, or 45,380 CPT 
codes for colonoscopy and at least one G0121 or G0105 code were identified. To increase the likelihood of capturing only screening colonoscopies, patients with prior history (by ICD-9 code) of colorectal cancer, ulcerative colitis, or Crohn's disease involving the colon during the 12-month baseline period were excluded. The index date was defined as the date of the first medical claim for screening colonoscopy. Patients were eligible for the study if they had 18 months of continuous insurance enrollment, defined as at least 12 months of baseline coverage prior to the index date and at least 6 months of follow-up coverage. All codes used in the analysis are listed in Table S1.

\section{Baseline characteristics}

Baseline characteristics for all patients include the demographics (sex, age, race/ethnicity, and type of health insurance plan), the Deyo-Charlson Modified Comorbidity Index, and the Revised Cardiac Risk Index (RCRI). The American Society of Anesthesiologists' (ASA) Physical Status Classification was noted whenever it was coded. The Deyo-Charlson modified index is an extensively studied and validated comorbidity index, which has been adapted for use with ICD-9 databases and includes 17 diseases that have been selected and weighted on the basis of the strength of their association with mortality. ${ }^{13}$

\section{Definition of average-risk and high-risk patients}

All patients were defined as either average-risk or highrisk, based upon their baseline characteristics of the RCRI score calculated using baseline period claims data. ${ }^{5} \mathrm{~A}$ subset of patients was also risk stratified by ASA status if the physical status CPT modifier was submitted either with the claim for screening colonoscopy or in the year prior to the index date. In the latter case, the most recent ASA status was used.

Average-risk patients were defined as those with an RCRI Class score of I or II, which means not having any risk factors or one risk factor of ischemic heart disease, history of congestive heart failure, history of cerebrovascular disease, insulin therapy for diabetes, or renal insufficiency. Patients with the risk factor of "insulin therapy for diabetes" must have had claims with an ICD-9 code for diabetes and a GPI code for insulin. High-risk patients were defined as those with an RCRI Class score of III or IV, which means two or more of the RCRI risk factors.

\section{Presence or absence of anesthesia provider}

The presence of an anesthesia provider was identified by the 00810 CPT code (anesthesia for lower intestinal endoscopic procedures, endoscope introduced distal to duodenum) submitted with the screening colonoscopy claim. If no claims for anesthesia services were associated with the submitted screening colonoscopy claim, then no anesthesia provider was presumed to be present.

\section{Outcome and process measurements}

Six months of follow-up claims were evaluated to identify whether the diagnosis of new colon cancer was made within 6 months of the colonoscopy; whether the colonoscopy was completed on the index date; whether repeating the colonoscopy was necessary; whether new primary ICD-9 diagnosis codes for MI and stroke were added within 7 days of the procedure; and whether hospital admission was required within 7 days. Each patient was followed for a 6-week period after the colonoscopy (latest follow-up was December 31, 2007). Adherence to ACG/ AGA/ASGE guidelines, which support the administration of sedation by non-anesthesia providers to average-risk patients receiving a screening colonoscopy, was measured. ${ }^{14}$

\section{Statistical analysis}

Descriptive statistics were produced for each set of the study measures. Mean and reported standard deviation for continuous variables, and frequency counts and percentage for categorical variables, were reported. McNemar's test was used to determine the statistical significance of differences in categorical measures, including comparison of the ratings based on RCRI score and ASA status.

The study cohorts for evaluating the impact of an anesthesia provider were obtained by matching patients who had an anesthesia provider on the index date with those without an anesthesia provider, using the propensity score method on a 1:1 basis. ${ }^{15}$ The Parsons algorithm selected matched pairs and the final cohorts, using the five digits match. ${ }^{16}$

Logistic regression using the generalized estimating equations (GEE) method was used to incorporate the matched pairs design and compare the effects of having an anesthesia provider present on the efficacy of colonoscopy in identifying colon cancer; the completion of the colonoscopy on the index date (as defined by coding that the examination was completed distal to the splenic flexure); the requirement for a repeat colonoscopy within 6 months; the development of an MI (a new primary ICD-9 code for the hospital encounter) 
within 7 days of colonoscopy; the incidence of stroke (a new primary ICD-9 code for the hospital encounter) within 7 days of colonoscopy; and the incidence of a hospital admission within 7 days of the screening colonoscopy in both groups. SAS (v.9.1; SAS Institute Inc., Cary, NC, USA) was used for all statistical analyses.

\section{Results}

\section{Baseline characteristics}

Table 1 reports the demographics and the frequency of comorbid conditions among the patients who received screening colonoscopies. Inclusion criteria were met by 63,750 Humana members. Only $6.52 \%$ of subjects had an ASA score submitted, of which the most commonly reported score was a physician status 3.The majority of patients had 0 or 1 RCRI factors ( $73 \%$ and $19 \%$, respectively). An anesthesia provider was present in $25.48 \%$ of screening colonoscopies.

\section{Provider type, outcomes, and adverse events}

High-risk patients were significantly more prevalent among the group having an anesthesia provider present during the colonoscopy $(9.3 \%$ vs $7.5 \%, P<0.0001)$. Through propensity scoring using the Charlson comorbidity index and RCRI score, 14,006 colonoscopy patients were matched (7,003 patients in the group without an anesthesia provider and 7,003 with an anesthesia provider). The demographics of the two matched groups are shown in Table 2.

MIs $(0.07 \%)$, strokes $(0.06 \%)$, and hospital admissions $(0.76 \%)$ within 7 days of the procedure were rare in both groups. A significant difference in the number of these events between the groups did not exist. The incidence of incomplete colonoscopies was not significantly different between those procedures performed with or without an anesthesia provider (1.39\% and $1.14 \%$, respectively). However, the incidence of repeat colonoscopies were significantly increased following a colonoscopy without an anesthesia provider as compared to with an anesthesia provider $(2.40 \%$ vs $1.78 \%, P<0.02)$. A nonsignificant trend toward a greater likelihood of a cancer diagnosis was present if an anesthesia provider was involved $(2.03 \%$ vs $1.7 \%$, $P=0.13$ ) (Tables 3 and 4).

\section{Adherence to guidelines}

Nine point three one percent of the 16,243 patients who had an anesthesia provider qualified as high-risk by RCRI criteria. The remaining $90.69 \%$ of the patients were average-risk.
Table I Baseline demographic and clinical characteristics in whole population

\begin{tabular}{|c|c|}
\hline Characteristics & $\begin{array}{l}\text { Whole population } \\
\mathrm{N}=63,750\end{array}$ \\
\hline \multicolumn{2}{|l|}{ Sex, N (\%) } \\
\hline Male & $26,945(42.27)$ \\
\hline Female & $36,805(57.73)$ \\
\hline \multicolumn{2}{|l|}{ Age group, N (\%) } \\
\hline $50-<55$ & $12,209(19.15)$ \\
\hline $55-<60$ & $10,283(16.13)$ \\
\hline $60-<65$ & $7,527(\mathrm{II} .8 \mathrm{I})$ \\
\hline $65-<70$ & $9,851(15.45)$ \\
\hline $70-<75$ & $10,367(16.26)$ \\
\hline $75-<80$ & $7,895(12.38)$ \\
\hline $80+$ & $5,618(8.8 I)$ \\
\hline Age, mean $(S D)$ & $65.80(10.11)$ \\
\hline \multicolumn{2}{|l|}{ Type of insurance, $\mathrm{N}(\%)$} \\
\hline \multicolumn{2}{|l|}{ Commercial } \\
\hline HMO & I2,084 (I8.96) \\
\hline PPO & $16,954(26.59)$ \\
\hline \multicolumn{2}{|l|}{ Medicare ADV } \\
\hline $\mathrm{HMO}$ & $25,972(40.74)$ \\
\hline PFFS & $8,06 \mid(12.64)$ \\
\hline PPO & $679(1.07)$ \\
\hline \multicolumn{2}{|l|}{ Geographic region, N (\%) } \\
\hline West & $3,669(5.76)$ \\
\hline South & $42,183(66.17)$ \\
\hline Northeast & $259(0.4 I)$ \\
\hline Midwest & $17,639(27.67)$ \\
\hline \multicolumn{2}{|l|}{ Charlson comorbidity, ${ }^{\mathrm{a}} \mathrm{N}(\%)$} \\
\hline Myocardial infarction (score =l) & $1,527(2.40)$ \\
\hline Congestive heart failure $($ score $=\mathrm{I})$ & $2,432(3.8 I)$ \\
\hline Peripheral vascular disease $($ score $=\mathrm{l}$ ) & $3,127(4.91)$ \\
\hline Cerebrovascular disease $($ score $=1)$ & $2,40 \mathrm{I}(3.77)$ \\
\hline Dementia $($ score $=\mathrm{l})$ & $237(0.37)$ \\
\hline Chronic pulmonary disease $($ score $=\mathrm{I})$ & $6,057(9.50)$ \\
\hline $\begin{array}{l}\text { Connective tissue disease-rheumatic } \\
\text { disease }(\text { score }=1)\end{array}$ & $1,330(2.09)$ \\
\hline Peptic ulcer disease (score $=\mathrm{I}$ ) & $558(0.88)$ \\
\hline Mild liver disease $($ score $=\mathrm{I})$ & I,33। (2.09) \\
\hline Diabetes without complications (score $=I$ ) & II,570 (I8.15) \\
\hline Diabetes with complications (score $=2$ ) & $2,84 \mid(4.46)$ \\
\hline Paraplegia and hemiplegia (score $=2$ ) & $160(0.25)$ \\
\hline Renal disease $($ score $=2)$ & I,833 (2.88) \\
\hline Cancer $($ score $=2)$ & $4,361(6.84)$ \\
\hline Moderate or severe liver disease $($ score $=3$ ) & $87(0.14)$ \\
\hline Metastatic carcinoma $($ score $=6)$ & $293(0.46)$ \\
\hline AIDS/HIV (score $=6)$ & $68(0.11)$ \\
\hline Charlson comorbidity score, ${ }^{a}$ mean (SD) & $0.81(1.43)$ \\
\hline Incomplete colonoscopy procedure, ${ }^{\mathrm{b}} \mathrm{N}(\%)$ & $810(1.27)$ \\
\hline \multicolumn{2}{|l|}{ Service site, ${ }^{\mathrm{b}} \mathrm{N}(\%)$} \\
\hline Ambulatory surgical center & $31,396(49.25)$ \\
\hline Hospital outpatient & $27,229(42.71)$ \\
\hline Physician office & $4,524(7.10)$ \\
\hline Hospital inpatient & $576(0.90)$ \\
\hline Other provider & $25(0.04)$ \\
\hline Presence of anesthesia provider, ${ }^{c} \mathrm{~N}(\%)$ & $16,243(25.48)$ \\
\hline
\end{tabular}

(Continued) 
Table I (Continued)

\begin{tabular}{ll}
\hline Characteristics & $\begin{array}{l}\text { Whole population } \\
\mathbf{N}=63,750\end{array}$ \\
\hline Personal history of colonic polyps, ${ }^{\mathrm{d}} \mathrm{N}(\%)$ & $3,693(5.79)$ \\
ASA status, ${ }^{\text {e }} \mathrm{N}(\%)$ & \\
PI & $344(0.54)$ \\
P2 & $\mathrm{I}, 587(2.49)$ \\
P3 & $2,085(3.27)$ \\
P4 & $136(0.21)$ \\
P5 & $4(0.01)$ \\
RCRI factors, ${ }^{f} \mathrm{~N}(\%)$ & \\
0 & $46,825(73.45)$ \\
I & $1 \mathrm{I}, 844(18.58)$ \\
2 & $3,709(5.82)$ \\
3 & $1,079(1.69)$ \\
4 & $257(0.40)$ \\
5 & $36(0.06)$ \\
\hline
\end{tabular}

Notes: aCharlson comorbidity was calculated using medical claims 365 days prior to index date; bincomplete procedure (CPT modifiers 52,53 , and 74 ), provider specialty, service site were defined by using medical claims containing the indexed colonoscopy procedure; 'presence of anesthesia provider was defined by the presence of CPT codes 00810 within any medical claim on index date. ${ }^{d}$ Personal history of colonic polyps was defined as follows: ICD-9 codes 211.3 , 21I.4, and VI2.72 within 365 days prior to index date, or VI2.72 on index date; ${ }^{e} \mathrm{CPT}$ modifiers from medical claims within I year prior to index date (including) were used to defined patients' ASA status. If a patient had different ASA statuses within this period, the latest one was used; fRCRI factors were defined using medical claims within 365 days prior to index date:

I) history of ischemic heart disease: 4 I0.xx, 4 II.xx, 4I2.xx, 4I3.xx, 4I4.xx

2) history of congestive heart failure: $428 . x x$

3) history of cerebrovascular disease: 43.

Abbreviations: ADV, Advantage; ASA, American Society of Anesthesiologists; CPT, Current Procedural Terminology; HMO, health maintenance organization; ICD-9, International Classification of Diseases Ninth revision; PPO, preferred provider organization; RCRI, Revised Cardiac Risk Index; SD, standard deviation PFFS, private fee-for-service.

The demographics of those with an anesthesia provider versus those without an anesthesia provider are shown on Table 5.

\section{Discussion}

This retrospective observational study of a large health benefits claims database evaluated the impact of the presence or absence of an anesthesia provider on major morbidity for a large population of average- and high-risk patients undergoing screening colonoscopies. Anesthesia providers were present $25.48 \%$ of the time, which is consistent with previously published US and Canadian rates of $27.8 \%$ and $19.1 \%$, respectively. ${ }^{6,17}$

Our study demonstrates that, in a population of predominantly average-risk patients, the presence of an anesthesia provider during a colonoscopy has no impact on the incidence of MI or stroke. However, a statistically significant decrease in the rate of repeated colonoscopies $(0.7 \%)$ was associated with the presence of an anesthesia provider. Although further study with sufficient power is needed to confirm the finding of a nonsignificant trend toward increased cancer detection, the decrease in repeat colonoscopies may be consistent with the nonsignificant trend toward greater cancer detection when an anesthesia provider is present. If a gastroenterologist were more inclined to avoid repeating a colonoscopy or aborting a procedure when an anesthesia provider manages the commonly occurring complications of hypoxemia (55.6\%), bradycardia (5.6\%), and hypotension (8.9\%), they may identify more lesions and be more confident that a sufficiently thorough exam was performed. ${ }^{18}$

Guidelines prepared jointly by the ACG, AGA, and ASGE, addressing the issue of sedation during routine lower endoscopic procedures, do not support the administration of moderate sedation by specially trained anesthesia providers to average-risk patients. However, for high-risk patients, the guidelines suggest that the administration of sedation by an anesthesiologist or other anesthesia provider might be considered. ${ }^{17}$ Conflicting results regarding outcomes and adverse events exist. ${ }^{19}$ The ASA has equivocated on whether the immediate availability of a provider with postgraduate training in anesthesiology increases the likelihood of a satisfactory outcome or decreases the associated risks associated with moderate sedation (more commonly performed on average-risk patients). For deep sedation or when procedures are performed on high-risk patients, the ASA agrees that the immediate availability of an anesthesiologist increases the likelihood of satisfactory sedation and decreases the likelihood of adverse outcomes. ${ }^{20}$ However, recent data suggests that the use of propofol by anesthesiologists has been associated with an increased risk of aspiration pneumonia among Medicare patients undergoing outpatient colonoscopy. ${ }^{12}$ Agostoni et al found that pulmonary aspiration is the most common significant complication of a colonoscopy. ${ }^{21}$ Additional evidence attributes the risk of respiratory complications and infections following endoscopies and colonoscopies to the depth of sedation achieved during the procedure. ${ }^{22}$

National guidelines regarding the use of anesthesia providers are not commonly followed in clinical practice. Currently, an endoscopist's decision to include an anesthesia provider has largely been dependent upon their level of comfort managing the administration of sedation and their desire to best meet the needs of their patients. The implementation of any guideline requires an understanding of existing trends in clinical practice and a commitment at the national, regional, and local levels to adapt evidence-based recommendations to available resources. In the absence of any outcome study, individual physicians may rationalize more care than less. 
Table 2 Baseline demographic and clinical characteristics after propensity score matching $(\mathrm{N}=14,006)$

\begin{tabular}{|c|c|c|c|}
\hline Characteristics & $\begin{array}{l}\text { Colonoscopy without } \\
\text { anesthesia provider } \\
\mathrm{N}=7,003\end{array}$ & $\begin{array}{l}\text { Colonoscopy with } \\
\text { anesthesia provider } \\
N=7,003\end{array}$ & $P$-value \\
\hline \multicolumn{4}{|l|}{ Sex, N (\%) } \\
\hline Male & $2,755(39.34)$ & $2,732(40.01)$ & \\
\hline Female & $4,248(60.66)$ & 4,27I (60.99) & $0.6905^{\mathrm{a}}$ \\
\hline Age, mean (SD) & $65.57(9.96)$ & $65.39(10.05)$ & $0.2925^{b}$ \\
\hline \multicolumn{4}{|l|}{ Type of insurance, $N(\%)$} \\
\hline \multicolumn{4}{|l|}{ Commercial } \\
\hline HMO & $\mathrm{I}, \mathrm{I} 72(\mathrm{I} 6.74)$ & I,254 (I7.9I) & $0.1190^{\mathrm{a}}$ \\
\hline PPO & $1,952(27.87)$ & $1,982(28.30)$ & \\
\hline \multicolumn{4}{|l|}{ Medicare ADV } \\
\hline $\mathrm{HMO}$ & $3,149(44.97)$ & $3,112(44.44)$ & \\
\hline PFFS & $674(9.62)$ & $607(8.67)$ & \\
\hline PPO & $56(0.80)$ & $48(0.69)$ & \\
\hline \multicolumn{4}{|l|}{ Geographic region, N (\%) } \\
\hline West & $237(3.38)$ & $208(2.97)$ & $0.1415^{\mathrm{a}}$ \\
\hline South & $5,936(84.76)$ & $6,030(86.11)$ & \\
\hline Northeast & $19(0.27)$ & $20(0.29)$ & \\
\hline Midwest & $811(11.58)$ & $745(10.64)$ & \\
\hline Charlson comorbidity score, mean (SD) & $0.68(1.32)$ & $0.67(1.32)$ & $0.5103^{b}$ \\
\hline \multicolumn{4}{|l|}{ Service site, N (\%) } \\
\hline Ambulatory surgical center & $4,390(62.69)$ & $4,298(61.37)$ & $0.2178^{a}$ \\
\hline Hospital outpatient & $2,166(30.93)$ & $2,206(31.50)$ & \\
\hline Physician office & $407(5.81)$ & $465(6.64)$ & \\
\hline Hospital inpatient & $37(0.53)$ & $32(0.46)$ & \\
\hline Other provider & $3(0.04)$ & $2(0.03)$ & \\
\hline \multicolumn{4}{|l|}{ Personal history of colonic polyps, N (\%) } \\
\hline Yes & $260(3.7 I)$ & $234(3.34)$ & $0.2337^{\mathrm{a}}$ \\
\hline \multicolumn{4}{|l|}{ RCRI risk group, N (\%) } \\
\hline High & $430(6.14)$ & $444(6.34)$ & $0.6248^{a}$ \\
\hline \multicolumn{4}{|l|}{ RCRI factors, $\mathrm{N}(\%)$} \\
\hline Ischemic heart disease (yes) & I,049 (I4.98) & $\mathrm{I}, 070(15.28)$ & $0.6205^{\mathrm{a}}$ \\
\hline Congestive heart failure (yes) & $239(3.41)$ & $257(3.67)$ & $0.4105^{\mathrm{a}}$ \\
\hline Cerebrovascular disease (yes) & $437(6.24)$ & $484(6.91)$ & $\left.0.109\right|^{\mathrm{a}}$ \\
\hline Renal insufficiency (yes) & $257(3.67)$ & $205(2.93)$ & $0.0139^{\mathrm{a}}$ \\
\hline Diabetes with insulin therapy (yes) & $176(2.51)$ & $147(2.10)$ & $0.1026^{\mathrm{a}}$ \\
\hline \multicolumn{4}{|l|}{ Hyperlipidemia, N (\%) } \\
\hline Yes & $4,686(66.91)$ & $4,648(66.37)$ & $0.4959^{\mathrm{a}}$ \\
\hline \multicolumn{4}{|l|}{ Hypertension, N (\%) } \\
\hline Yes & $4,156(59.35)$ & $4,204(60.03)$ & $0.4083^{\mathrm{a}}$ \\
\hline \multicolumn{4}{|l|}{ Obesity, N (\%) } \\
\hline Yes & $404(5.77)$ & $443(6.33)$ & $0.1668^{\mathrm{a}}$ \\
\hline
\end{tabular}

Notes: ${ }^{a}$-value for comparison between anesthesia without provider and with provider, calculated by chi-square test; ${ }^{b} P$-value for comparison between anesthesia without provider and with provider, calculated by $t$-test with equal variance.

Abbreviations: ADV, Advantage; HMO, health maintenance organization; PFFS, private fee-for-service; PPO, preferred provider organization; RCRI, Revised Cardiac Risk Index; SD, standard deviation.

Our study contains a number of limitations related to its retrospective nature and use of insurance claims data. The "presence of anesthesia provider" does not differentiate between the presence of an anesthesiologist (or the subset of board-certified anesthesiologists) or a CRNA. Perhaps measuring outcomes separately would reveal different outcomes between the two provider groups. Similarly, in the "absence of anesthesia provider" group, almost all patients still received some degree of sedation. However, no method existed to determine if the sedation was administered by another physician or registered nurse. Furthermore, the medications used to provide sedation could not be identified. Medications represent a potential confounding variable, as they differ in their safety and pharmacologic profiles. As an example, anesthesia providers are more likely to utilize medications such as propofol, which has more profound pharmacodynamic effects than other sedatives. Data on the type of anesthesia administered (general anesthesia, deep 
Table 3 Comparison of colonoscopy outcomes

\begin{tabular}{|c|c|c|c|c|c|c|c|c|}
\hline \multirow[t]{2}{*}{ Outcomes } & \multirow{2}{*}{$\begin{array}{l}\text { Colonoscopy } \\
\text { without anesthesia } \\
\text { provider } \\
\mathrm{N}=7,003\end{array}$} & \multirow{2}{*}{$\begin{array}{l}\text { Colonoscopy } \\
\text { with anesthesia } \\
\text { provider } \\
\mathrm{N}=7,003\end{array}$} & \multicolumn{3}{|c|}{ Unadjusted } & \multicolumn{3}{|c|}{ Adjusted* } \\
\hline & & & OR & $95 \% \mathrm{Cl}$ & $P$-value & OR & $95 \% \mathrm{Cl}$ & $P$-value \\
\hline $\begin{array}{l}\text { Completed colonoscopy } \\
\text { on index day, } \mathrm{N}(\%)\end{array}$ & $6,906(98.61)$ & 6,923 (98.86) & 1.22 & $0.90-1.64$ & 0.2020 & 1.23 & $0.91-1.66$ & 0.1797 \\
\hline $\begin{array}{l}\text { Repeated colonoscopy within } \\
I 80 \text { days post-index day, } \mathrm{N}(\%)^{* *}\end{array}$ & $168(2.40)$ & $125(1.78)$ & 0.74 & $0.59-0.93$ & 0.0114 & 0.75 & $0.59-0.96$ & 0.0195 \\
\hline $\begin{array}{l}\text { Colorectal cancer identified on } \\
\text { index day and within } 180 \text { days } \\
\text { post-index day, } \mathrm{N}(\%)\end{array}$ & $119(1.7)$ & $142(2.03)$ & 1.20 & $0.94-1.53$ & 0.1487 & 1.21 & $0.95-1.55$ & 0.1266 \\
\hline Colon & $104(1.49)$ & $128(1.83)$ & 1.24 & $0.95-1.60$ & 0.1110 & 1.25 & $0.96-1.63$ & 0.0942 \\
\hline Rectum and anus & $72(1.03)$ & $94(1.34)$ & 1.31 & $0.96-1.78$ & 0.0867 & 1.33 & $0.97-1.81$ & 0.0761 \\
\hline $\begin{array}{l}\text { Hospital admission on index } \\
\text { day and within } 7 \text { days } \\
\text { post-index day, } \mathrm{N}(\%)\end{array}$ & $58(0.83)$ & $49(0.70)$ & 0.97 & $0.86-1.09$ & 0.6205 & 0.97 & $0.86-1.09$ & 0.5848 \\
\hline
\end{tabular}

Notes: *For MI, adjusting for age, sex, and previous history of MI. For stroke, adjusting for age, sex, and previous history of cerebrovascular disease. For other outcomes, adjusting for variables used for propensity score matching (age, sex, geographic region, RCRI group, etc) and status of colonoscopy procedure (not used for completed colonoscopy outcome). GEE analysis was performed to adjust for correlation within matched pairs; **all types of colonoscopy procedures defined in Table 4.

Abbreviations: $\mathrm{Cl}$, confidence interval; GEE, generalized estimating equations; MI, myocardial infarction; OR, odds ratio; RCRI, Revised Cardiac Risk Index.

sedation, or moderate sedation) was not available. However, given the extremely low incidence of complications, the likely that further stratification of providers, depth of anesthesia, or type of sedative medications administered would change our conclusions is low. Finally, polyp yield from the colonoscopy procedure and histology and staging for cases of colon cancer identified were not available in the dataset, which might have caused a missed benefit of having an anesthesia provider present, if effectiveness of the screening examination was considered using that data. There were a very small number of cardiovascular events from which to draw conclusions about the choice of professionals providing sedation.
Evaluating the effectiveness of the therapies and the usefulness of anesthesia providers for routine screenings, treatments, or symptom management is a national imperative of medical research. This study helps formulate updated policies related to endoscopic sedation and advances the understanding of health care expenditures about the outcomes related to sedation during colonoscopy. Through additional carefully conducted research and thoughtful analysis, physicians and guideline-setting organizations will be able to make recommendations on the optimal use of health resources, for the benefit of individual patients and the health of our society.

Table 4 Comparison of cardiovascular outcomes

\begin{tabular}{|c|c|c|c|c|c|c|c|c|}
\hline \multirow[t]{2}{*}{ Outcomes } & \multirow{2}{*}{$\begin{array}{l}\text { Colonoscopy } \\
\text { without anesthesia } \\
\text { provider } \\
\mathrm{N}=7,003\end{array}$} & \multirow{2}{*}{$\begin{array}{l}\text { Colonoscopy } \\
\text { with anesthesia } \\
\text { provider } \\
\mathrm{N}=7,003\end{array}$} & \multicolumn{3}{|c|}{ Unadjusted } & \multicolumn{3}{|c|}{ Adjusted* } \\
\hline & & & OR & $95 \% \mathrm{Cl}$ & $P$-value & OR & $95 \% \mathrm{Cl}$ & $P$-value \\
\hline $\begin{array}{l}\text { Ml on index day and within } \\
7 \text { days post-index day, } \mathrm{N}(\%)\end{array}$ & $4(0.06)$ & $13(0.19)$ & 3.25 & $1.06-9.99$ & 0.0392 & 3.20 & $1.03-9.90$ & 0.0442 \\
\hline $\begin{array}{l}\text { MI (primary diagnosis) on index } \\
\text { day and within } 7 \text { days post-index } \\
\text { day, } \mathrm{N}(\%)\end{array}$ & $3(0.04)$ & $7(0.10)$ & 2.33 & $0.60-9.04$ & 0.2195 & 2.25 & $0.58-8.77$ & 0.2422 \\
\hline $\begin{array}{l}\text { Stroke on index day and within } \\
7 \text { days post-index day, } N(\%)\end{array}$ & $10(0.14)$ & $10(0.14)$ & 1.00 & $0.42-2.4 I$ & 1.0000 & 0.90 & $0.38-2.18$ & 0.8234 \\
\hline $\begin{array}{l}\text { Stroke (primary diagnosis) } \\
\text { on index day and within } 7 \text { days } \\
\text { post-index day, } \mathrm{N}(\%)\end{array}$ & $5(0.07)$ & $4(0.06)$ & 0.80 & $0.21-2.98$ & 0.7394 & 0.76 & $0.20-2.81$ & 0.6765 \\
\hline
\end{tabular}

Notes: *For MI, adjusting for age, sex, and previous history of MI. For stroke, adjusting for age, sex, and previous history of cerebrovascular disease. GEE analysis was performed to adjust for correlation within matched pairs.

Abbreviations: $\mathrm{Cl}$, confidence interval; GEE, generalized estimating equations; $\mathrm{MI}$, myocardial infarction; OR, odds ratio. 
Table 5 Baseline demographic and clinical characteristics $(\mathrm{N}=63,750)$

\begin{tabular}{|c|c|c|c|}
\hline Characteristics & $\begin{array}{l}\text { Colonoscopy without } \\
\text { anesthesia provider } \\
\mathrm{N}=47,507\end{array}$ & $\begin{array}{l}\text { Colonoscopy with } \\
\text { anesthesia provider } \\
N=16,243\end{array}$ & $P$-value \\
\hline \multicolumn{4}{|l|}{ Sex, N (\%) } \\
\hline Male & 20,425 (42.99) & $6,520(40.14)$ & \\
\hline Female & $27,082(57.01)$ & $9,723(59.86)$ & $<0.000 I^{a}$ \\
\hline Age, mean (SD) & $65.28(10.10)$ & $67.31(9.99)$ & $<0.000 \mathrm{I}^{\mathrm{b}}$ \\
\hline \multicolumn{4}{|l|}{ Type of insurance, $N(\%)$} \\
\hline \multicolumn{4}{|l|}{ Commercial } \\
\hline HMO & $9,278(19.53)$ & $2,806(17.28)$ & $<0.000 \mathrm{I}^{\mathrm{a}}$ \\
\hline PPO & $14,019(29.51)$ & $2,935(18.07)$ & \\
\hline \multicolumn{4}{|l|}{ Medicare ADV } \\
\hline $\mathrm{HMO}$ & $16,885(35.54)$ & $9,087(55.94)$ & \\
\hline PFFS & $6,803(14.32)$ & $\mathrm{I}, 258(7.74)$ & \\
\hline PPO & $522(1.10)$ & $157(0.97)$ & \\
\hline \multicolumn{4}{|l|}{ Geographic region, N (\%) } \\
\hline West & $3,339(7.03)$ & $330(2.03)$ & $<0.000 \mathrm{I}^{\mathrm{a}}$ \\
\hline South & 27,454 (57.79) & $14,729(90.68)$ & \\
\hline Northeast & $115(0.24)$ & $144(0.89)$ & \\
\hline Midwest & $16,599(34.94)$ & $\mathrm{I}, 040(6.40)$ & \\
\hline Charlson comorbidity score, mean (SD) & $0.76(1.40)$ & $0.93(1.52)$ & $<0.000 \mathrm{I}^{\mathrm{c}}$ \\
\hline \multicolumn{4}{|l|}{ Service site, N (\%) } \\
\hline Ambulatory surgical center & I9,7|7 (4I.50) & II,679 (7I.90) & $<0.000 \mathrm{I}^{\mathrm{a}}$ \\
\hline Hospital outpatient & $23,568(49.6 I)$ & $3,66 \mathrm{I}(22.54)$ & \\
\hline Physician office & $3,693(7.77)$ & $831(5.12)$ & \\
\hline Hospital inpatient & $507(1.07)$ & $69(0.42)$ & \\
\hline Other provider & $22(0.05)$ & $3(0.02)$ & \\
\hline \multicolumn{4}{|l|}{ Personal history of colonic polyps, N (\%) } \\
\hline Yes & $1,990(4.19)$ & I,703 (I0.48) & $<0.000 I^{a}$ \\
\hline \multicolumn{4}{|l|}{ RCRI risk group, N (\%) } \\
\hline High & $3,568(7.5 \mathrm{I})$ & $1,513(9.31)$ & $<0.000 I^{\mathrm{a}}$ \\
\hline \multicolumn{4}{|l|}{ RCRI factors, $\mathrm{N}(\%)$} \\
\hline Ischemic heart disease (yes) & $7,666(16.14)$ & $3,449(21.23)$ & $<0.000 \mathrm{I}^{\mathrm{a}}$ \\
\hline Congestive heart failure (yes) & $2,161(4.55)$ & $791(4.87)$ & $0.0929^{a}$ \\
\hline Cerebrovascular disease (yes) & $3,55 \mathrm{I}(7.47)$ & $\mathrm{I}, 544(9.5 \mathrm{I})$ & $<0.000 I^{\mathrm{a}}$ \\
\hline Renal insufficiency (yes) & $\mathrm{I}, 835(3.86)$ & $788(4.85)$ & $<0.000 \mathrm{I}^{\mathrm{a}}$ \\
\hline Diabetes with insulin therapy (yes) & $\mathrm{I}, 422(2.99)$ & $500(3.08)$ & $0.5844^{\mathrm{a}}$ \\
\hline \multicolumn{4}{|l|}{ Hyperlipidemia, N (\%) } \\
\hline Yes & $28,902(60.84)$ & II,353 (69.89) & $<0.000 I^{\mathrm{a}}$ \\
\hline \multicolumn{4}{|l|}{ Hypertension, N (\%) } \\
\hline Yes & $27,665(58.23)$ & $10,514(64.73)$ & $<0.000 I^{\mathrm{a}}$ \\
\hline \multicolumn{4}{|l|}{ Obesity, N (\%) } \\
\hline Yes & 2,97 I (6.25) & $\mathrm{I}, 295(7.97)$ & $<0.000 \mathrm{I}^{\mathrm{a}}$ \\
\hline
\end{tabular}

Notes: ${ }^{a} P$-value for comparison between colonoscopy without anesthesia provider and with anesthesia provider, calculated by chi-square test; ${ }^{b} P$-value for comparison between colonoscopy without anesthesia provider and with anesthesia provider, calculated by $t$-test with equal variance; $c$-value for comparison between colonoscopy without anesthesia provider and with anesthesia provider, calculated by $t$-test with unequal variance.

Abbreviations: ADV, Advantage; HMO, health maintenance organization; PFFS, private fee-for-service; PPO, preferred provider organization; RCRI, Revised Cardiac Risk Index; SD, standard deviation.

\section{Conclusion}

The presence of an anesthesia provider during a screening colonoscopy did not affect the incidence of completed colonoscopies or the incidence of significant morbidity. MI and stroke following screening colonoscopies are very rare. A nonstatistically significant trend toward increased cancer detection was found, when an anesthesia provider was present. Furthermore, repeat colonoscopies were significantly increased following a colonoscopy without an anesthesia provider. Adherence to 2004 published guidelines by several societies representing gastroenterologists regarding the use of anesthesia providers was poor.

\section{Author contributions}

All authors contributed toward data analysis, drafting and revising the paper and agree to be accountable for all aspects of the work. 


\section{Acknowledgments}

We would like to thank Valerie A Arkoosh, MD, MPH, of the University of Pennsylvania - Department of Anesthesiology for her assistance with this project. We would also like to thank Ms Garla Connor and Miss Krystie Cabrales for their assistance with manuscript preparation.

\section{Disclosure}

Qianli Ma and Claudia Uribe are employed by Humana. John Hanna was employed by Humana at the time the project was conducted. The other authors report no conflicts of interest in this work.

\section{References}

1. Jemal A, Siegel R, Ward E, et al. Cancer Statistics, 2009. CA Cancer J Clin. 2009;59(4):225-249.

2. Levin B, Lieberman DA, McFarland B, et al; American Cancer Society Colorectal Cancer Advisory Group; US Multi-Society Task Force; American College of Radiology Colon Cancer Committee. Screening and surveillance for the early detection of colorectal cancer and adenomatous polyps, 2008: a joint guideline from the American Cancer Society, the US Multi-Society Task Force on Colorectal Cancer, and the American College of Radiology. CA Cancer J Clin. 2008;58(3):130-160.

3. Centers for Disease Control and Prevention (CDC). Colorectal cancer test use among persons aged $>$ or $=50$ years - United States, 2001 . MMWR Morb Mortal Wkly Rep. 2003;52(10):193-196.

4. Walsh JM, Terdiman JP. Colorectal cancer screening: scientific review. JAMA. 2003;289(10):1288-1296.

5. Lee TH, Mercantonio ER, Mangione CM, et al. Derivation and prospective validation of a simple index for prediction of cardiac risk of major noncardiac surgery. Circulation. 1999;100(10):1043-1049.

6. Cohen LB, Wecsler JS, Gaetano JN, et al. Endoscopic sedation in the United States: results from a nationwide survey. Am J Gastroenterol. 2006;101(5):967-974.

7. Atkinson M, Schmulewitz N. Downstream hospital charges generated from endoscopic ultrasound procedures are greater than those from colonoscopies. Clin Gastroenterol Hepatol. 2009;7(8):862-867.

8. Cohen LB. Production pressure in endoscopy: balancing quantity and quality. Gastroenterology. 2008;135(6):1842-1844.

9. Official Propofol FDA Monograph [webpage on the Internet]. Drugs. com. Available from: http://www.drugs.com/pro/propofol.html. Accessed January 16, 2015.
10. Cohen LB, Delegge MH, Aisenberg J, et al; AGA Institute. AGA Institute review of endoscopic sedation. Gastroenterology. 2007;133(2): 675-701.

11. Aetna Retreats on Anesthesia Limits During Colonoscopy [webpage on the Internet]. Wall Street Journal Online. Available from: http:// blogs.wsj.com/health/2008/02/27/aetna-retreats-on-anesthesia-limitsduring-colonoscopy/. Accessed January 16, 2015. Digestive Disease Week (DDW) 2009: Abstract 722. Presented June 1, 2009. Available from: http://www.medscape.com/viewarticle/703648? src=mpnews\& spon=7\&uac=36797CY. Accessed January 16, 2015.

12. Cooper GS, Kou TD, Rex DK. Complications following colonoscopy with anesthesia assistance: a population-based analysis. JAMA Intern Med. 2013;173(7):551-556.

13. Deyo RA, Cherkin DC, Ciol MA. Adapting a clinical comorbidity index for use with ICD-9-CM administrative databases. J Clin Epidemiol. 1992;45(6):613-619.

14. Gastroenterology Societies Reach Consensus on Recommendations for Sedation During Endoscopic Procedures [webpage on the Internet]. Bethesda, MD: American Gastroenterological Association. Available from: http://www.gastro.org. Accessed January 16, 2015.

15. D'Agostino RB Jr. Propensity score methods for bias reduction in the comparison of a treatment to a nonrandomized control group. Stat Med. 1998;17(19):2265-2281.

16. Parsons LS. Performing a 1:N case-control match on propensity score: Proceedings of the Twenty-Ninth Annual SAS ${ }^{\circledR}$ Users Group International Conference, Montréal, Canada, 9-12 May 2004. Cary, NC: SAS Institute Inc.; 2004.

17. Alharbi O, Rabeneck L, Paszat LF, et al. A population-based analysis of outpatient colonoscopy in adults assisted by an anesthesiologist. Anesthesiology. 2009;111(4):734-740.

18. Khalid-de Bakker CA, Jonkers DM, Hameeteman W, de Ridder RJ, Masclee AA, Stockbrügger RW. Cardiopulmonary events during primary colonoscopy screening in an average risk population. Neth J Med. 2011;69(4):186-191.

19. Vargo JJ, Holub JL, Faigel DO, Lieberman DA, Eisen GM. Risk factors for cardiopulmonary events during propofol-mediated upper endoscopy and colonoscopy. Aliment Pharmacol Ther. 2006;24(6):955-963.

20. American Society of Anesthesiologists Task Force on Sedation and Analgesia by Non-Anesthesiologists. Practice guidelines for sedation and analgesia by non-anesthesiologists. Anesthesiology. 2002;96(4):1004-1017.

21. Agostoni M, Fanti L, Gemma M, Pasculli N, Beretta L, Testoni PA. Adverse events during monitored anesthesia care for GI endoscopy: an 8-year experience. Gastrointest Endosc. 2011;74(2):266-275.

22. Friedrich K, Scholl SG, Beck S, et al; bng-Study-Group. Respiratory complications in outpatient endoscopy with endoscopist-directed sedation. J Gastrointestin Liver Dis. 2014;23(3):255-259. 


\section{Supplementary table}

Table S I

\begin{tabular}{|c|c|}
\hline CPT code & Description \\
\hline 00810 & Presence of anesthesia provider \\
\hline 45355 & Colonoscopy, rigid or flexible, transabdominal via colostomy, single or multiple \\
\hline 45378 & $\begin{array}{l}\text { Colonoscopy, flexible, proximal to splenic flexure; diagnostic, with or without collection of specimen(s) by brushing or washing, } \\
\text { with or without colon decompression }\end{array}$ \\
\hline 45380 & Colonoscopy, flexible, proximal to splenic flexure; with biopsy, single or multiple \\
\hline Modifier 52 & Incomplete procedure \\
\hline Modifier 53 & Incomplete procedure \\
\hline Modifier 74 & Incomplete procedure \\
\hline Modifier PI & Normal healthy patient \\
\hline Modifier P2 & Patient with mild systemic disease \\
\hline Modifier P3 & Patient with severe systemic disease \\
\hline Modifier P4 & Patient with severe systemic disease that is a constant threat to life \\
\hline Modifier P5 & Moribund patient who is not expected to survive without the operation \\
\hline \multicolumn{2}{|l|}{ G code } \\
\hline G0I2I & Colorectal screening; colonoscopy on individual not meeting criteria for high risk \\
\hline G0I05 & Colorectal screening; colonoscopy on individual meeting criteria for high risk \\
\hline \multicolumn{2}{|r|}{ 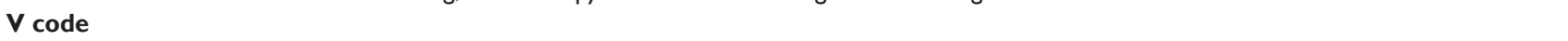 } \\
\hline V10.05 & Personal history of malignant neoplasm of large intestine \\
\hline V10.06 & Personal history of malignant neoplasm of rectum, rectosigmoid junction, and anus \\
\hline \multicolumn{2}{|r|}{ 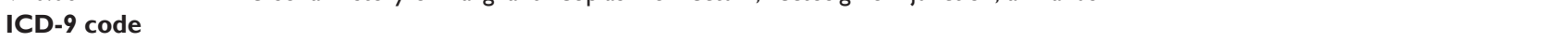 } \\
\hline 153 & Malignant neoplasm of colon \\
\hline 153.0 & Malignant neoplasm of hepatic flexure \\
\hline 153.1 & Malignant neoplasm of transverse colon \\
\hline 153.2 & Malignant neoplasm of descending colon \\
\hline 153.3 & Malignant neoplasm of sigmoid colon \\
\hline 153.4 & Malignant neoplasm of cecum \\
\hline 153.5 & Malignant neoplasm of appendix \\
\hline 153.6 & Malignant neoplasm of ascending colon \\
\hline 153.7 & Malignant neoplasm of splenic flexure \\
\hline 153.8 & Malignant neoplasm of other specified sites of large intestine \\
\hline 153.9 & Malignant neoplasm of colon, unspecified site \\
\hline 154 & Malignant neoplasm of rectum, rectosigmoid junction, and anus \\
\hline 154.0 & Malignant neoplasm of rectosigmoid junction \\
\hline 154.1 & Malignant neoplasm of rectum \\
\hline 154.2 & Malignant neoplasm of anal canal \\
\hline 154.3 & Malignant neoplasm of anus, unspecified site \\
\hline 154.8 & Malignant neoplasm of other sites of rectum, rectosigmoid junction, and anus \\
\hline \multicolumn{2}{|l|}{ ICD-9 code } \\
\hline 230.3 & Carcinoma in situ of colon \\
\hline 230.6 & Carcinoma in situ of rectum \\
\hline 230.7 & Carcinoma in situ of anal canal \\
\hline 230.8 & Carcinoma in situ of anus, unspecified \\
\hline 235.2 & Neo uncertain behavior \\
\hline 239.0 & Neo unspecified \\
\hline 555 & Regional enteritis \\
\hline 555.1 & Regional enteritis, large intestine \\
\hline 555.2 & Regional enteritis, small intestine with large intestine \\
\hline 555.9 & Regional enteritis, unspecified site \\
\hline 556 & Ulcerative colitis \\
\hline 556.0 & Ulcerative (chronic) enterocolitis \\
\hline 556.1 & Ulcerative (chronic) ileocolitis \\
\hline 556.2 & Ulcerative (chronic) proctitis \\
\hline 556.3 & Ulcerative (chronic) proctosigmoiditis \\
\hline 556.4 & Pseudopolyposis of colon \\
\hline 556.5 & Left-sided ulcerative (chronic) colitis \\
\hline 556.6 & Universal ulcerative (chronic) colitis \\
\hline 556.8 & Other ulcerative colitis \\
\hline 556.9 & Ulcerative colitis, unspecified \\
\hline
\end{tabular}


Table SI (Continued)

\begin{tabular}{|c|c|}
\hline CPT code & Description \\
\hline 410 & Acute myocardial infarction \\
\hline 410.0 & Acute myocardial infarction of anterolateral wall \\
\hline 410.00 & Acute myocardial infarction of anterolateral wall, episode of care unspecified \\
\hline 410.01 & Acute myocardial infarction of anterolateral wall, initial episode of care \\
\hline 410.02 & Acute myocardial infarction of anterolateral wall, subsequent episode of care \\
\hline 410.1 & Acute myocardial infarction of other anterior wall \\
\hline 410.0 & Acute myocardial infarction of other anterior wall, episode of care unspecified \\
\hline 410.11 & Acute myocardial infarction of other anterior wall, initial episode of care \\
\hline 410.12 & Acute myocardial infarction of other anterior wall, subsequent episode of care \\
\hline 410.2 & Acute myocardial infarction of inferolateral wall \\
\hline 410.20 & Acute myocardial infarction of inferolateral wall, episode of care unspecified \\
\hline 410.21 & Acute myocardial infarction of inferolateral wall, initial episode of care \\
\hline 410.22 & Acute myocardial infarction of inferolateral wall, subsequent episode of care \\
\hline 410.3 & Acute myocardial infarction of inferoposterior wall \\
\hline 410.30 & Acute myocardial infarction of inferoposterior wall, episode of care unspecified \\
\hline 410.31 & Acute myocardial infarction of inferoposterior wall, initial episode of care \\
\hline 410.32 & Acute myocardial infarction of inferoposterior wall, subsequent episode of care \\
\hline 410.4 & Acute myocardial infarction of other inferior wall \\
\hline 410.40 & Acute myocardial infarction of other inferior wall, episode of care unspecified \\
\hline 410.41 & Acute myocardial infarction of other inferior wall, initial episode of care \\
\hline \multicolumn{2}{|l|}{ ICD-9 code } \\
\hline 410.42 & Acute myocardial infarction of other inferior wall, subsequent episode of care \\
\hline 410.5 & Acute myocardial infarction of other lateral wall \\
\hline 410.50 & Acute myocardial infarction of other lateral wall, episode of care unspecified \\
\hline $4|0.5|$ & Acute myocardial infarction of other lateral wall, initial episode of care \\
\hline 410.52 & Acute myocardial infarction of other lateral wall, subsequent episode of care \\
\hline 410.6 & Acute myocardial infarction, true posterior wall infarction \\
\hline 410.60 & Acute myocardial infarction, true posterior wall infarction, episode of care unspecified \\
\hline 410.61 & Acute myocardial infarction, true posterior wall infarction, initial episode of care \\
\hline 410.62 & Acute myocardial infarction, true posterior wall infarction, subsequent episode of care \\
\hline 410.7 & Acute myocardial infarction, subendocardial infarction \\
\hline 410.70 & Acute myocardial infarction, subendocardial infarction, episode of care unspecified \\
\hline 410.71 & Acute myocardial infarction, subendocardial infarction, initial episode of care \\
\hline 410.72 & Acute myocardial infarction, subendocardial infarction, subsequent episode of care \\
\hline 410.8 & Acute myocardial infarction of other specified sites \\
\hline 410.80 & Acute myocardial infarction of other specified sites, episode of care unspecified \\
\hline 410.81 & Acute myocardial infarction of other specified sites, initial episode of care \\
\hline 410.82 & Acute myocardial infarction of other specified sites, subsequent episode of care \\
\hline 410.9 & Acute myocardial infarction, unspecified site \\
\hline 410.90 & Acute myocardial infarction, unspecified site, episode of care unspecified \\
\hline 410.91 & Acute myocardial infarction, unspecified site, initial episode of care \\
\hline 410.92 & Acute myocardial infarction, unspecified site, subsequent episode of care \\
\hline 411 & Other acute and subacute forms of ischemic heart disease \\
\hline 411.0 & Postmyocardial infarction syndrome \\
\hline 411.1 & Intermediate coronary syndrome \\
\hline 411.8 & Other acute and subacute forms of ischemic heart disease \\
\hline 411.81 & Acute coronary occlusion without myocardial infarction \\
\hline 411.89 & Other acute and subacute form of ischemic heart disease \\
\hline 412 & Old myocardial infarction \\
\hline 413 & Angina pectoris \\
\hline 413.0 & Angina decubitus \\
\hline $4 \mid 3.1$ & Prinzmetal angina \\
\hline 413.9 & Other and unspecified angina pectoris \\
\hline 414 & Other forms of chronic ischemic heart disease \\
\hline 414.0 & Coronary atherosclerosis \\
\hline 414.00 & Coronary atherosclerosis of unspecified type of vessel, native, or graft \\
\hline $4|4.0|$ & Coronary atherosclerosis of native coronary artery \\
\hline 414.02 & Coronary atherosclerosis of autologous vein bypass graft \\
\hline $4 \mid 4.03$ & Coronary atherosclerosis of nonautologous biological bypass graft \\
\hline
\end{tabular}


Table SI (Continued)

\begin{tabular}{|c|c|}
\hline CPT code & Description \\
\hline $4 \mid 4.04$ & Coronary atherosclerosis of artery bypass graft \\
\hline $4 \mid 4.05$ & Coronary atherosclerosis of unspecified type of bypass graft \\
\hline \multicolumn{2}{|l|}{ ICD-9 code } \\
\hline $4 \mid 4.06$ & Coronary atherosclerosis, of native coronary artery of transplanted heart \\
\hline $4 \mid 4.07$ & Coronary atherosclerosis, of bypass graft (artery) (vein) of transplanted heart \\
\hline $4 \mid 4.1$ & Aneurysm and dissection of heart \\
\hline 414.10 & Aneurysm of heart \\
\hline $4 \mid 4.11$ & Aneurysm of coronary vessels \\
\hline 414.12 & Dissection of coronary artery \\
\hline 414.19 & Other aneurysm of heart \\
\hline 414.2 & Chronic total occlusion of coronary artery \\
\hline $4 \mid 4.8$ & Other specified forms of chronic ischemic heart disease \\
\hline 414.9 & Unspecified chronic ischemic heart disease \\
\hline 430 & Subarachnoid hemorrhage \\
\hline 431 & Intracerebral hemorrhage \\
\hline 432 & Other and unspecified intracranial hemorrhage \\
\hline 432.0 & Nontraumatic extradural hemorrhage \\
\hline 432. 1 & Subdural hemorrhage \\
\hline 432.9 & Unspecified intracranial hemorrhage \\
\hline 433 & Occlusion and stenosis of precerebral arteries \\
\hline 433.0 & Occlusion and stenosis of basilar artery \\
\hline 433.00 & Occlusion and stenosis of basilar artery without mention of cerebral infarction \\
\hline 433.01 & Occlusion and stenosis of basilar artery with cerebral infarction \\
\hline 433.1 & Occlusion and stenosis of carotid artery \\
\hline 433.10 & Occlusion and stenosis of carotid artery without mention of cerebral infarction \\
\hline 433.11 & Occlusion and stenosis of carotid artery with cerebral infarction \\
\hline 433.2 & Occlusion and stenosis of vertebral artery \\
\hline 433.20 & Occlusion and stenosis of vertebral artery without mention of cerebral infarction \\
\hline 433.21 & Occlusion and stenosis of vertebral artery with cerebral infarction \\
\hline 433.3 & Occlusion and stenosis of multiple and bilateral precerebral arteries \\
\hline 433.30 & Occlusion and stenosis of multiple and bilateral precerebral arteries without mention of cerebral infarction \\
\hline 433.31 & Occlusion and stenosis of multiple and bilateral precerebral arteries with cerebral infarction \\
\hline 433.8 & Occlusion and stenosis of other specified precerebral artery \\
\hline 433.80 & Occlusion and stenosis of other specified precerebral artery without mention of cerebral infarction \\
\hline 433.81 & Occlusion and stenosis of other specified precerebral artery with cerebral infarction \\
\hline 433.9 & Occlusion and stenosis of unspecified precerebral artery \\
\hline 433.90 & Occlusion and stenosis of unspecified precerebral artery without mention of cerebral infarction \\
\hline 433.91 & Occlusion and stenosis of unspecified precerebral artery with cerebral infarction \\
\hline 434 & Occlusion of cerebral arteries \\
\hline 434.0 & Cerebral thrombosis \\
\hline 434.00 & Cerebral thrombosis without mention of cerebral infarction \\
\hline 434.01 & Cerebral thrombosis with cerebral infarction \\
\hline \multicolumn{2}{|l|}{ ICD-9 code } \\
\hline 434.1 & Cerebral embolism \\
\hline 434. 10 & Cerebral embolism without mention of cerebral infarction \\
\hline 434.1I & Cerebral embolism with cerebral infarction \\
\hline 434.9 & Unspecified cerebral artery occlusion \\
\hline 434.90 & Unspecified cerebral artery occlusion without mention of cerebral infarction \\
\hline 434.91 & Unspecified cerebral artery occlusion with cerebral infarction \\
\hline 435 & Transient cerebral ischemia \\
\hline 435.0 & Basilar artery syndrome \\
\hline 435.1 & Vertebral artery syndrome \\
\hline 435.2 & Subclavian steal syndrome \\
\hline 435.3 & Vertebrobasilar artery syndrome \\
\hline 435.8 & Other specified transient cerebral ischemias \\
\hline 435.9 & Unspecified transient cerebral ischemia \\
\hline 436 & Acute, but ill-defined, cerebrovascular disease \\
\hline 437 & Other and ill-defined cerebrovascular disease \\
\hline 437.0 & Cerebral atherosclerosis \\
\hline 437. 1 & Other generalized ischemic cerebrovascular disease \\
\hline 437.2 & Hypertensive encephalopathy \\
\hline 437.3 & Cerebral aneurysm, nonruptured \\
\hline 437.4 & Cerebral arteritis \\
\hline
\end{tabular}


Table SI (Continued)

\begin{tabular}{|c|c|}
\hline CPT code & Description \\
\hline 437.5 & Moyamoya disease \\
\hline 437.6 & Nonpyogenic thrombosis of intracranial venous sinus \\
\hline 437.7 & Transient global amnesia \\
\hline 437.8 & Other ill-defined cerebrovascular disease \\
\hline 437.9 & Unspecified cerebrovascular disease \\
\hline 438 & Late effects of cerebrovascular disease \\
\hline 438.0 & Cognitive deficits due to cerebrovascular disease \\
\hline 438. I & Speech and language deficits due to cerebrovascular disease \\
\hline 439.10 & Unspecified speech and language deficit due to cerebrovascular disease \\
\hline 438.11 & Aphasia due to cerebrovascular disease \\
\hline 438.12 & Dysphasia due to cerebrovascular disease \\
\hline 438.19 & Other speech and language deficits due to cerebrovascular disease \\
\hline 438.2 & Hemiplegia/hemiparesis due to cerebrovascular disease \\
\hline 438.20 & Hemiplegia affecting unspecified side due to cerebrovascular disease \\
\hline 438.21 & Hemiplegia affecting dominant side due to cerebrovascular disease \\
\hline 438.22 & Hemiplegia affecting nondominant side due to cerebrovascular disease \\
\hline 438.3 & Monoplegia of upper limb due to cerebrovascular disease \\
\hline 438.30 & Monoplegia of upper limb affecting unspecified side due to cerebrovascular disease \\
\hline 438.31 & Monoplegia of upper limb affecting dominant side due to cerebrovascular disease \\
\hline 438.32 & Monoplegia of upper limb affecting nondominant side due to cerebrovascular disease \\
\hline \multicolumn{2}{|l|}{ ICD-9 code } \\
\hline 438.4 & Monoplegia of lower limb due to cerebrovascular disease \\
\hline 438.40 & Monoplegia of lower limb affecting unspecified side due to cerebrovascular disease \\
\hline 438.41 & Monoplegia of lower limb affecting dominant side due to cerebrovascular disease \\
\hline 438.42 & Monoplegia of lower limb affecting nondominant side due to cerebrovascular disease \\
\hline 438.5 & Other paralytic syndrome due to cerebrovascular disease \\
\hline 438.50 & Other paralytic syndrome affecting unspecified side due to cerebrovascular disease \\
\hline 438.51 & Other paralytic syndrome affecting dominant side due to cerebrovascular disease \\
\hline 438.52 & Other paralytic syndrome affecting nondominant side due to cerebrovascular disease \\
\hline 438.6 & Alteration of sensations as late effect of cerebrovascular disease \\
\hline 438.7 & Disturbance of vision as late effect of cerebrovascular disease \\
\hline 438.8 & Other late effects of cerebrovascular disease due to cerebrovascular disease \\
\hline 438.81 & Apraxia due to cerebrovascular disease \\
\hline 438.82 & Dysphagia due to cerebrovascular disease \\
\hline 438.83 & Facial weakness as late effect of cerebrovascular disease \\
\hline 438.84 & Ataxia as late effect of cerebrovascular disease \\
\hline 438.85 & Vertigo as late effect of cerebrovascular disease \\
\hline 438.89 & Other late effects of cerebrovascular disease \\
\hline 438.9 & Unspecified late effects of cerebrovascular disease due to cerebrovascular disease \\
\hline 428 & Heart failure \\
\hline 428.0 & Congestive heart failure, unspecified \\
\hline 428. 1 & Left heart failure \\
\hline 428.2 & Systolic heart failure \\
\hline 428.20 & Unspecified systolic heart failure \\
\hline 428.21 & Acute systolic heart failure \\
\hline 428.22 & Chronic systolic heart failure \\
\hline 428.23 & Acute on chronic systolic heart failure \\
\hline 428.3 & Diastolic heart failure \\
\hline 428.30 & Unspecified diastolic heart failure \\
\hline 428.31 & Acute diastolic heart failure \\
\hline 428.32 & Chronic diastolic heart failure \\
\hline 428.33 & Acute on chronic diastolic heart failure \\
\hline 428.4 & Combined systolic and diastolic heart failure \\
\hline 428.40 & Unspecified combined systolic and diastolic heart failure \\
\hline 428.41 & Acute combined systolic and diastolic heart failure \\
\hline 428.42 & Chronic combined systolic and diastolic heart failure \\
\hline 428.43 & Acute on chronic combined systolic and diastolic heart failure \\
\hline 428.9 & Unspecified heart failure \\
\hline 250 & Diabetes mellitus \\
\hline 250.0 & Diabetes mellitus without mention of complication \\
\hline
\end{tabular}

(Continued) 
Table SI (Continued)

\begin{tabular}{|c|c|}
\hline CPT code & Description \\
\hline \multicolumn{2}{|c|}{ ICD-9 code } \\
\hline 250.00 & Diabetes mellitus without mention of complication, type II or unspecified type, not stated as uncontrolled \\
\hline 250.01 & Diabetes mellitus without mention of complication, type I (juvenile type), not stated as uncontrolled \\
\hline 250.02 & Diabetes mellitus without mention of complication, type II or unspecified type, uncontrolled \\
\hline 250.03 & Diabetes mellitus without mention of complication, type I (juvenile type), uncontrolled \\
\hline 250.1 & Diabetes with ketoacidosis \\
\hline 250.10 & Diabetes with ketoacidosis, type II or unspecified type, not stated as uncontrolled \\
\hline 250.11 & Diabetes with ketoacidosis, type I (juvenile type), not stated as uncontrolled \\
\hline 250.12 & Diabetes with ketoacidosis, type II or unspecified type, uncontrolled \\
\hline 250.13 & Diabetes with ketoacidosis, type I (juvenile type), uncontrolled \\
\hline 250.2 & Diabetes with hyperosmolarity \\
\hline 250.20 & Diabetes with hyperosmolarity, type II or unspecified type, not stated as uncontrolled \\
\hline 250.21 & Diabetes with hyperosmolarity, type I (juvenile type), not stated as uncontrolled \\
\hline 250.22 & Diabetes with hyperosmolarity, type II or unspecified type, uncontrolled \\
\hline 250.23 & Diabetes with hyperosmolarity, type I (juvenile type), uncontrolled \\
\hline 250.3 & Diabetes with other coma \\
\hline 250.30 & Diabetes with other coma, type II or unspecified type, not stated as uncontrolled \\
\hline 250.31 & Diabetes with other coma, type I (juvenile type), not stated as uncontrolled \\
\hline 250.32 & Diabetes with other coma, type II or unspecified type, uncontrolled \\
\hline 250.33 & Diabetes with other coma, type I (juvenile type), uncontrolled \\
\hline 250.4 & Diabetes with renal manifestations \\
\hline 250.40 & Diabetes with renal manifestations, type II or unspecified type, not stated as uncontrolled \\
\hline 250.41 & Diabetes with renal manifestations, type I (juvenile type), not stated as uncontrolled \\
\hline 250.42 & Diabetes with renal manifestations, type II or unspecified type, uncontrolled \\
\hline 250.43 & Diabetes with renal manifestations, type I (juvenile type), uncontrolled \\
\hline 250.5 & Diabetes with ophthalmic manifestations \\
\hline 250.50 & Diabetes with ophthalmic manifestations, type II or unspecified type, not stated as uncontrolled \\
\hline 250.51 & Diabetes with ophthalmic manifestations, type I (juvenile type), not stated as uncontrolled \\
\hline 250.52 & Diabetes with ophthalmic manifestations, type II or unspecified type, uncontrolled \\
\hline 250.53 & Diabetes with ophthalmic manifestations, type I (juvenile type), uncontrolled \\
\hline 250.6 & Diabetes with neurological manifestations \\
\hline 250.60 & Diabetes with neurological manifestations, type II or unspecified type, not stated as uncontrolled \\
\hline 250.61 & Diabetes with neurological manifestations, type I (juvenile type), not stated as uncontrolled \\
\hline 250.62 & Diabetes with neurological manifestations, type II or unspecified type, uncontrolled \\
\hline 250.63 & Diabetes with neurological manifestations, type I (juvenile type), uncontrolled \\
\hline 250.7 & Diabetes with peripheral circulatory disorders \\
\hline 250.70 & Diabetes with peripheral circulatory disorders, type II or unspecified type, not stated as uncontrolled \\
\hline 250.71 & Diabetes with peripheral circulatory disorders, type I (juvenile type), not stated as uncontrolled \\
\hline 250.72 & Diabetes with peripheral circulatory disorders, type II or unspecified type, uncontrolled \\
\hline 250.73 & Diabetes with peripheral circulatory disorders, type I (juvenile type), uncontrolled \\
\hline \multicolumn{2}{|l|}{ ICD-9 code } \\
\hline 250.8 & Diabetes with other specified manifestations \\
\hline 250.80 & Diabetes with other specified manifestations, type II or unspecified type, not stated as uncontrolled \\
\hline 250.81 & Diabetes with other specified manifestations, type I (juvenile type), not stated as uncontrolled \\
\hline 250.82 & Diabetes with other specified manifestations, type II or unspecified type, uncontrolled \\
\hline 250.83 & Diabetes with other specified manifestations, type I (juvenile type), uncontrolled \\
\hline 250.9 & Diabetes with unspecified complication \\
\hline 250.90 & Diabetes with unspecified complication, type II or unspecified type, not stated as uncontrolled \\
\hline 250.91 & Diabetes with unspecified complication, type I (juvenile type), not stated as uncontrolled \\
\hline 250.92 & Diabetes with unspecified complication, type II or unspecified type, uncontrolled \\
\hline 250.93 & Diabetes with unspecified complication, type I (juvenile type), uncontrolled \\
\hline 581 & Nephrotic syndrome \\
\hline 581.0 & Nephrotic syndrome with lesion of proliferative glomerulonephritis \\
\hline 581.1 & Nephrotic syndrome with lesion of membranous glomerulonephritis \\
\hline 581.2 & Nephrotic syndrome with lesion of membranoproliferative glomerulonephritis \\
\hline 581.3 & Nephrotic syndrome with lesion of minimal change glomerulonephritis \\
\hline 581.8 & Nephrotic syndrome with other specified pathological lesion in kidney \\
\hline 581.81 & Nephrotic syndrome with other specified pathological lesion in kidney in diseases classified elsewhere \\
\hline
\end{tabular}


Table SI (Continued)

\begin{tabular}{|c|c|}
\hline CPT code & Description \\
\hline 581.89 & Other nephrotic syndrome with specified pathological lesion in kidney \\
\hline 581.9 & Nephrotic syndrome with unspecified pathological lesion in kidney \\
\hline 582 & Chronic glomerulonephritis \\
\hline 582.0 & Chronic glomerulonephritis with lesion of proliferative glomerulonephritis \\
\hline 582.1 & Chronic glomerulonephritis with lesion of membranous glomerulonephritis \\
\hline 582.2 & Chronic glomerulonephritis with lesion of membranoproliferative glomerulonephritis \\
\hline 582.4 & Chronic glomerulonephritis with lesion of rapidly progressive glomerulonephritis \\
\hline 582.8 & Chronic glomerulonephritis with other specified pathological lesion in kidney \\
\hline 582.81 & Chronic glomerulonephritis with other specified pathological lesion in kidney in diseases classified elsewhere \\
\hline 582.89 & Other chronic glomerulonephritis with specified pathological lesion in kidney \\
\hline 582.9 & Chronic glomerulonephritis with unspecified pathological lesion in kidney \\
\hline 585 & Chronic renal failure \\
\hline 585.1 & Chronic kidney disease, Stage I \\
\hline 585.2 & Chronic kidney disease, Stage II (mild) \\
\hline 585.3 & Chronic kidney disease, Stage III (moderate) \\
\hline 585.4 & Chronic kidney disease, Stage IV (severe) \\
\hline 585.5 & Chronic kidney disease, Stage $\mathrm{V}$ \\
\hline 585.6 & End stage renal disease \\
\hline 585.9 & Chronic kidney disease, unspecified \\
\hline 587 & Unspecified renal sclerosis \\
\hline 588 & Disorders resulting from impaired renal function \\
\hline 588.0 & Renal osteodystrophy \\
\hline \multicolumn{2}{|l|}{ ICD-9 code } \\
\hline 588. & Nephrogenic diabetes insipidus \\
\hline 588.8 & Other specified disorder resulting from impaired renal function \\
\hline 588.89 & Other specified disorders resulting from impaired renal function \\
\hline 588.9 & Unspecified disorder resulting from impaired renal function \\
\hline \multicolumn{2}{|l|}{ GPI code } \\
\hline 2710101000 & Insulin (Regular) Inj I00 Unit/ML \\
\hline 2710101000 & Insulin (Regular) Inj 80 Unit/ML \\
\hline 2710101000 & Insulin (Regular) Inj 40 Unit/ML \\
\hline 2710102000 & Insulin Isophane Inj 40 Unit/ML \\
\hline 2710102000 & Insulin Isophane Inj 100 Unit/ML \\
\hline 2710102000 & Insulin Isophane Inj 80 Unit/ML \\
\hline 2710103000 & Insulin Protamine Zinc Inj 40 Unit/ML \\
\hline 2710103000 & Insulin Protamine Zinc Inj 100 Unit/ML \\
\hline 2710104000 & Insulin Zinc Inj 40 Unit/ML \\
\hline 2710104000 & Insulin Zinc Inj 80 Unit/ML \\
\hline 2710104000 & Insulin Zinc Inj I00 Unit/ML \\
\hline 2710105000 & Insulin Zinc, Extended Inj I00 Unit/ML \\
\hline 2710105000 & Insulin Zinc, Extended Inj 40 Unit/ML \\
\hline 2710106000 & Insulin Zinc, Prompt Inj I00 Unit/ML \\
\hline 2710106000 & Insulin Zinc, Prompt Inj 40 Unit/ML \\
\hline 2710201000 & Insulin Regular (Beef) Inj I00 Unit/ML \\
\hline 2710202000 & Insulin Isophane (Beef) Inj I00 Unit/ML \\
\hline 2710203000 & Insulin Protamine Zinc (Beef) Inj 100 Unit/ML \\
\hline 2710204000 & Insulin Zinc (Beef) Inj I00 Unit/ML \\
\hline 2710205000 & Insulin Zinc, Extended (Beef) Inj I00 Unit/ML \\
\hline 2710206000 & Insulin Zinc, Prompt (Beef) Inj I00 Unit/ML \\
\hline 2710301000 & Insulin Regular (Pork) Inj 500 Unit/ML \\
\hline 2710301000 & Insulin Regular (Pork) Inj 100 Unit/ML \\
\hline 2710301000 & Insulin Regular (Pork) Inj 40 Unit/ML \\
\hline 2710302000 & Insulin Isophane (Pork) Inj I00 Unit/ML \\
\hline 2710303000 & Insulin Protamine Zinc (Pork) Inj I00 Unit/ML \\
\hline 2710304000 & Insulin Zinc (Pork) Inj I00 Unit/ML \\
\hline 2710306000 & Insulin Zinc, Prompt (Pork) Inj 100 Unit/ML \\
\hline 2710307000 & Insulin Regular and Isophane (Pork) Inj I00 Unit/ML \\
\hline 2710400200 & Insulin Aspart Inj 100 Unit/ML \\
\hline
\end{tabular}


Table SI (Continued)

\begin{tabular}{ll}
\hline CPT code & Description \\
\hline 2710400300 & Insulin Glargine Inj I00 Unit/ML \\
2710400500 & Insulin Lispro (Human) Inj I00 Unit/ML \\
2710401000 & Insulin Regular (Human) Inj I00 Unit/ML \\
2710401500 & Insulin Regular (Human) Inj Buffered I00 Unit/ML \\
GPI code & \\
2710402000 & Insulin Isophane (Human) Inj I00 Unit/ML \\
2710403000 & Insulin Zinc (Human) Inj I00 Unit/ML \\
2710405000 & Insulin Zinc, Extended (Human) Inj I00 Unit/ML \\
2710407000 & Insulin Aspart Prot and Aspart (Human) Inj I00 Unit/ML (70-30) \\
2710408000 & Insulin Lispro and Lispro Prot (Human) Inj I00 Unit/ML (25-75) \\
2710409000 & Insulin Isophane and Regular (Human) Inj I00 Unit/ML (50-50) \\
2710409000 & Insulin Isophane and Regular (Human) Inj I00 Unit/ML (70-30) \\
2710409000 & Insulin Regular and Isophane (Human) Inj I00 Unit/ML (30-70) \\
\hline
\end{tabular}

Abbreviations: CPT, Current Procedural Terminology; GPI, Generic Product Identifier; ICD-9, International Classification of Diseases Ninth revision; Inj, injected.

\section{Publish your work in this journal}

The Journal of Multidisciplinary Healthcare is an international, peerreviewed open-access journal that aims to represent and publish research in healthcare areas delivered by practitioners of different disciplines. This includes studies and reviews conducted by multidisciplinary teams as well as research which evaluates the results or conduct of such teams or healthcare processes in general. The journal covers a wide range of areas and welcomes submissions from practitioners at all levels, from all over the world. The manuscript management system is completely online and includes a very quick and fair peer-review system. Visit http://www.dovepress.com/testimonials.php to read real quotes from published authors.

Submit your manuscript here: http://www.dovepress.com/journal-of-multidisciplinary-healthcare-journal 